\title{
Lactate Dehydrogenase Prior to Transarterial Hepatic Chemoperfusion Predicts Survival and Time to Progression in Patients with Uveal Melanoma Liver Metastases
}

\section{Laktatdehydrogenase vor transarterieller hepatischer Chemoperfusion prognostiziert das Überleben und den Tumorprogress bei Patienten mit Lebermetastasen bei Aderhautmelanom}

Authors

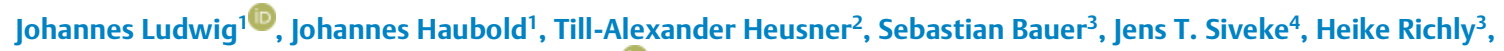
Axel Wetter ${ }^{1}$, Lale Umutlu' ${ }^{1}$, Jens $M$. Theysohn ${ }^{1 \mathbb{C}}$

Affiliations

1 Department of Diagnostic and Interventional Radiology and Neuroradiology, University Hospital Essen, Germany

2 Clinic for Diagnostic and Interventional Radiology/ Neuroradiology, Sankt-Elisabeth-Hospital Gütersloh, Gütersloh, Germany

3 West German Cancer Center, University Hospital Essen, Germany

4 German Consortium for Translational Cancer Research (DKTK), partner location University Hospital Essen, University Hospital Essen, Germany

\section{Key words} uveal melanoma, infusions, intra-arterial, melphalan, liver, chemotherapy

received 25.04.2020

accepted 19.10.2020

published online 21.12.2020

Bibliography

Fortschr Röntgenstr 2021; 193: 683-691

DOI 10.1055/a-1299-1627

ISSN 1438-9029

(C) 2020. Thieme. All rights reserved.

Georg Thieme Verlag KG, Rüdigerstraße 14,

70469 Stuttgart, Germany

\section{Correspondence}

Prof. Jens M Theysohn

Institute for Diagnostic and Interventional Radiology and Neuroradiology, University Hospital Essen, Hufelandstr. 55, 45122 Essen, Germany

Tel.: +49/2 01/72384536

Jens.Theysohn@uk-essen.de

\section{ZUSAMMENFASSUNG}

Ziel Beurteilung der Serum-Laktatdehydrogenase (LDH) als prätherapeutischer prognostischer Faktor bei Patienten mit Lebermetastasen eines Aderhautmelanoms, die mit der transarteriellen hepatischen Chemoperfusion (THC) behandelt wurden.

Material und Methoden 56 Patienten (48\% männlich, medianes Alter: 63,5 Jahre) erhielten im Median 4 Behandlungen. Die Kaplan-Meier-Analyse für das mediane Gesamtüberleben und die Zeit bis zur hepatischen Tumorprogression (TTP; $95 \%-\mathrm{KI})$ in Monaten sowie das Cox-Proportional-HazardModell für die univariate (UVA) und multivariate Analyse (MVA) zur Bewertung des Risikoquotienten (HR) wurden berechnet.

Ergebnisse Das mediane Überleben betrug 9,4 Monate. Der LDH-Wert vor der ersten Behandlung war der stärkste Prädiktor für das Überleben mit 19,8 Monaten für normale ( $\leqq 280$ Einheiten/Liter $(\mathrm{U} / \mathrm{L})$ ), 9,7 Monaten für mittlere (>280-<1000 U/L) und 3,84 Monaten für hohe ( $\geqq 1000 \mathrm{U} / \mathrm{L})$ LDH-Werte. Die LDH war der signifikanteste Vorhersagewert für die TTP mit 8, 4 und 1 Monaten für normale, mittlere bzw. hohe LDH-Werte. Die UVA identifizierte mittlere $(16,5)$ und hohe $(77,3)$ LDH-Werte, Bilirubin > Obergrenze des Normalbereichs (ULN) $(2,89)$, alkalische Phosphatase $>1,5$ ULN $(6,8)$, Leukozyten > ULN $(4,2)$, Gamma-Glutamyltransferase (GGT) > ULN (7), extrahepatische Metastasen $(1,8)$ und Leberläsionen $\geq 5 \mathrm{~cm}(3,6)$ als signifikante Prädiktoren für ein kürzeres Überleben. Die MVA bestätigte mittlere $(5,0)$ und hohe $(27,1)$ LDH-Werte, Bilirubin $(5,7)$, GGT $(2,9)$ und eine Tumorgröße von $\geq 5 \mathrm{~cm}(3,7)$ als unabhängige signifikante Prädiktoren für das Überleben. Patienten mit einer LDHAbnahme vs. einer Zunahme $>10 \%$ zwischen der ersten und zweiten Behandlung (median: 38 Tage) überlebten länger (14,6 vs. 4,3 Monate) und zeigten eine spätere Progression (7 vs. 1 Monate). 
Schlussfolgerung Ein erhöhter prätherapeutischer LDHWert ist ein wesentlicher und robuster OS- und TTP-Prädiktor, der es potenziell ermöglicht die Patienten zu identifizieren, welche am meisten von der transarteriellen hepatischen Chemoperfusion profitieren.

\section{Kernaussagen:}

- Prätherapeutisches LDH ist der stärkste prognostische Faktor für das Überleben und die Tumorprogression

- Eine therapiebedingte LDH-Abnahme > $10 \%$ zwischen der ersten und zweiten Behandlung ist mit einem längeren OS und TTP assoziiert

- Niedrigere LDH, Bilirubin und Gamma-Glutamyl-Transferase Werte sowie kleinere Tumore sind unabhängige prätherapeutische Prädiktoren für ein längeres Gesamtüberleben

- Extrahepatische Metastasen haben keinen unabhängigen Einfluss auf das Gesamtüberleben

\section{ABSTRACT}

Purpose To assess serum lactate dehydrogenase (LDH) as a pretreatment prognostic factor in patients with uveal melanoma liver metastases treated with transarterial hepatic chemoperfusion (THC).

Materials and Methods 56 patients ( $48 \%$ male, median age: 63.5 years) underwent a median of 4 THC sessions. KaplanMeier for median overall survival (OS) and time to hepatic progression (TTP; $95 \% \mathrm{Cl}$ ) in months and Cox proportional hazards model for uni- (UVA) \& multivariate analyses (MVA) for hazard ratio (HR) evaluation were calculated.

Results The median OS was 9.4 months. The pretreatment $\mathrm{LDH}$ value before $1 \mathrm{st}$ THC was the strongest OS predictor with 19.8 months for normal ( $\leqq 280$ units per liter $(\mathrm{U} / \mathrm{L})$ ), 9.7 for intermediate ( $>280-<1000 \mathrm{U} / \mathrm{L}$ ), and 3.84 months for high ( $\geqq 1000 \mathrm{U} / \mathrm{L}) \mathrm{LDH}$. LDH significantly predicted a median
TTP with 8 months, 4 months, and 1 month for normal, intermediate, and high $\mathrm{LDH}$, respectively. UVA revealed intermediate (16.5) and high (77.3) LDH, bilirubin > the upper limit of normal (ULN) (2.89), alkaline phosphatase > 1.5 ULN (6.8), leukocytes > ULN (4.2), gamma-glutamyl transferase (GGT) $>$ ULN (7), extrahepatic metastases (1.8) and liver lesions $\geq 5 \mathrm{~cm}$ (3.6) as significant predictors for worse OS. MVA confirmed intermediate (5) and high (27.1) LDH, bilirubin (5.7), GGT (2.9), and tumor size $\geq 5 \mathrm{~cm}$ (3.7) as significant independent predictors for worse OS. Patients with decreasing vs. increasing $\mathrm{LDH}>10 \%$ between 1 st and 2 nd THC (median: 38 days) survived longer (14.6 vs. 4.3 months) and progressed later (7 months vs. 1 month).

Conclusion Elevated pretreatment serum LDH is an essential and robust OS and TTP predictor, potentially allowing for the identification of patients benefiting most from transarterial hepatic chemoperfusion.

\section{Key Points:}

- Pretherapeutic LDH is the most reliable prognosticator for OS and TTP

- Therapy-related LDH decrease $>10 \%$ between $1^{\text {st }}$ and $2^{\text {nd }}$ THC had prolonged OS and TTP

- Lower Values of LDH, bilirubin, gamma-glutamyl transferase, and tumor size are independent pretherapeutic predictors for longer OS

- Extrahepatic metastases do not have an independent influence on overall survival

\section{Citation Format}

- Ludwig J, Haubold J, Heusner T et al. Lactate Dehydrogenase Prior to Transarterial Hepatic Chemoperfusion Predicts Survival and Time to Progression in Patients with Uveal Melanoma Liver Metastases. Fortschr Röntgenstr 2021; 193: 683-691

\section{Introduction}

Uveal melanoma is a rare malignant disease arising from melanocytes of the eye's uveal tract accounting for $5 \%$ of all melanomas $[1,2]$. Uveal melanoma is most commonly seen in Caucasians, with yearly incidence rates varying from two per million in southern to up to $\geq 8$ per million in northern European countries [3]. Despite tremendous efforts to effectively treat localized tumors, approximately $50-90 \%$ of all patients will eventually develop metastases $[4,5]$. Nevertheless, the majority of patients with liver metastases are not considered suitable for curative treatment options at the time of diagnosis. In the case of prevalent liver disease, liver-directed therapies have proven to be effective and safe alternatives compared to systemic chemotherapy [1]. At our institution, patients with prevalent liver disease are routinely treated with transarterial hepatic chemoperfusion (THC) as a palliative treatment option demonstrating significantly lower rates of hematological severe adverse events and prolonged progressionfree survival compared to intravenous chemotherapy [6].
Serum lactate dehydrogenase (LDH) is a well-acknowledged, although non-specific tumor marker correlating with increasing tumor burden and is believed to represent the tumor's growth potential as well as the invasive nature in many tumors, including uveal melanoma. Moreover, higher serum LDH levels have been reported as a negative prognostic marker reflecting more advanced tumor stages correlating with shorter overall survival times [7, 8].

The ability to estimate effectiveness for each treatment option is critical for decision making and for setting expectations for patients and their relatives. The purpose of this study was to assess transarterial hepatic chemoperfusion as a palliative treatment option in patients with hepatic uveal melanoma metastases and to evaluate the prognostic value of pretreatment factors with a focus on serum lactate dehydrogenase as an independent prognostic biomarker for survival and time to tumor progression to understand better which patient group may potentially benefit from therapy. 


\section{Methods}

Study population and design: The local institutional review board approved this retrospective single-center database analysis. It has been conducted in compliance with the Health Insurance Portability and Accountability Act. Performed procedures involving human participants were in accordance with the ethical standards of the institutional and the national research committee and with the 1964 Helsinki declaration and its later amendments or comparable ethical standards. The institutional review board waived informed consent. All treatment decisions were based on multidisciplinary tumor board meetings according to the institutional standard.

Fifty-six consecutive patients treated first between May 2003 and March 2008 were included. The inclusion criteria for this study were as follows: I) At least 18 years of age, II) imaging or biopsy-proven uveal melanoma liver metastases, III) treatment of liver metastases with THC, and IV) reported LDH serum levels within two weeks before the first treatment. Patient data were retrieved from medical records, including medical history, laboratory results, and imaging workup prior to and post treatment. Assessed laboratory pretreatment factors were measured within two weeks before the first THC procedure. Different aspects of this patient cohort have been reported previously [9] with now available death dates for the entire patient cohort.

Transarterial hepatic chemoperfusion procedure: THC was performed as described previously in detail [9]. Briefly, access was obtained via the right or left femoral artery by placing a $5 \mathrm{Fr}$ catheter sheath. Placement of a microcatheter into the hepatic arteries, either in the proper hepatic artery or separately into the liver-supplying arteries in case of unequal distribution of the left and right liver lobes or accessory vessels. Chemoperfusion of the entire liver parenchyma was performed for 45-60 minutes. Treatment started with melphalan, and in case of clinically evident progression (not RECIST based in clinical routine), the treatment agent dose was increased or switched to another drug if chemoperfusion was still considered the appropriate treatment. Overall, patients were treated with melphalan only $(n=27)$ or with varying agents $(n=29)$ consecutively (melphalan, fotemustine, dacarbazine, mitomycin, doxorubicin, or gemcitabine) at the discretion of the treating physicians. Drug dosage was adapted to each patient's body surface area.

Endpoint assessment: Baseline and follow-up imaging were performed using cross-sectional imaging one day before each THC session. Response assessment evaluation for research purposes was conducted according to the RECIST 1.0 criteria. The date of death was obtained for all patients from the patients' records, from the family physicians, or the register of deaths.

Statistics: Kaplan-Meier for overall survival (OS) and time to hepatic progression (TTP), including the $95 \%$ confidence interval $(95 \% \mathrm{Cl})$, were calculated by applying the log-rank test. Contingency table statistics were performed using the Pearson method. Hazard ratios (HR), including the $95 \% \mathrm{Cl}$, were calculated utilizing the Cox proportional hazards model for uni- (UVA) \& multivariate (MVA) analyses. Statistical calculations were performed using JMP Pro 13.0 (SAS Institute Inc.). P-values < 0.05 were considered statistically significant.
- Table 1 Baseline characteristics.

- Tab. 1 Zusammensetzung der Kohorte.

\begin{tabular}{|c|c|}
\hline characteristics & $\begin{array}{l}\text { number of patients }(\%) / \\
\text { median values }\end{array}$ \\
\hline total number of patients & 56 \\
\hline gender (male) & 27 (48.2\%) \\
\hline median age in years (range) & $63.5(25-82)$ \\
\hline \multicolumn{2}{|l|}{ prior therapy } \\
\hline prior chemotherapy & $17(30.4 \%)$ \\
\hline - fotemustine & $7(12.5 \%)$ \\
\hline - treosulfan & $7(12.5 \%)$ \\
\hline - gemcitabine & $6(10.7 \%)$ \\
\hline - dacarbazine & $5(8.9 \%)$ \\
\hline - other & $17(30.4 \%)$ \\
\hline Prior thermal ablation & $1(1.8 \%)$ \\
\hline Prior liver resection & $3(5.3 \%)$ \\
\hline $\begin{array}{l}\text { systemic therapy after last transarterial } \\
\text { chemoperfusion }\end{array}$ & $19(33.9 \%)$ \\
\hline $\begin{array}{l}\text { limited extrahepatic metastases at time } \\
\text { of } 1^{\text {st }} \text { transarterial chemoperfusion }\end{array}$ & $22(39.3 \%)$ \\
\hline $\begin{array}{l}\text { median maximal tumor size in cm } \\
\text { (range) }\end{array}$ & $6(1-16)$ \\
\hline \multicolumn{2}{|l|}{ lobar tumor involvement } \\
\hline - bilobar & $54(96.4 \%)$ \\
\hline - unilobar & $2(3.6 \%)$ \\
\hline
\end{tabular}

\section{Results}

\section{Patient characteristics}

56 patients ( $48.2 \%$ male) with a median age of 63.5 years (range: 25-82 years) were included in this study. The median time between primary diagnosis and occurrence of hepatic metastases was 28.5 months (range: $0-144$ months), and the first THC session was performed after a median of 1.5 months (range: 0.5-27 months) following the diagnosis of liver metastases. A median of 4.5 (range: 1-15) THC treatments were conducted per patient. Additional baseline characteristics are presented in - Table 1.

\section{Survival analysis}

Overall survival: Following the diagnosis of liver metastases, patients survived a median of 13.3 months ( $95 \% \mathrm{Cl}$ : 9.5-15.7). The median cohort OS following the first THC treatment was 9.6 months (95\% Cl: 5.5-13.3) ( Fig. 1a) with 1, 2, 3, and 5year survival rates of $42.9 \%, 8.9 \%, 5.4 \%$, and $3.6 \%$, respectively.

Pretreatment prognostic factors: Several pretreatment factors before the $1^{\text {st }} \mathrm{THC}$ were identified in the univariate analysis to predict the median OS, with the pretreatment serum LDH being recognized as the strongest one $(p<0.0001)(\triangleright$ Table 2$)$. Patients 

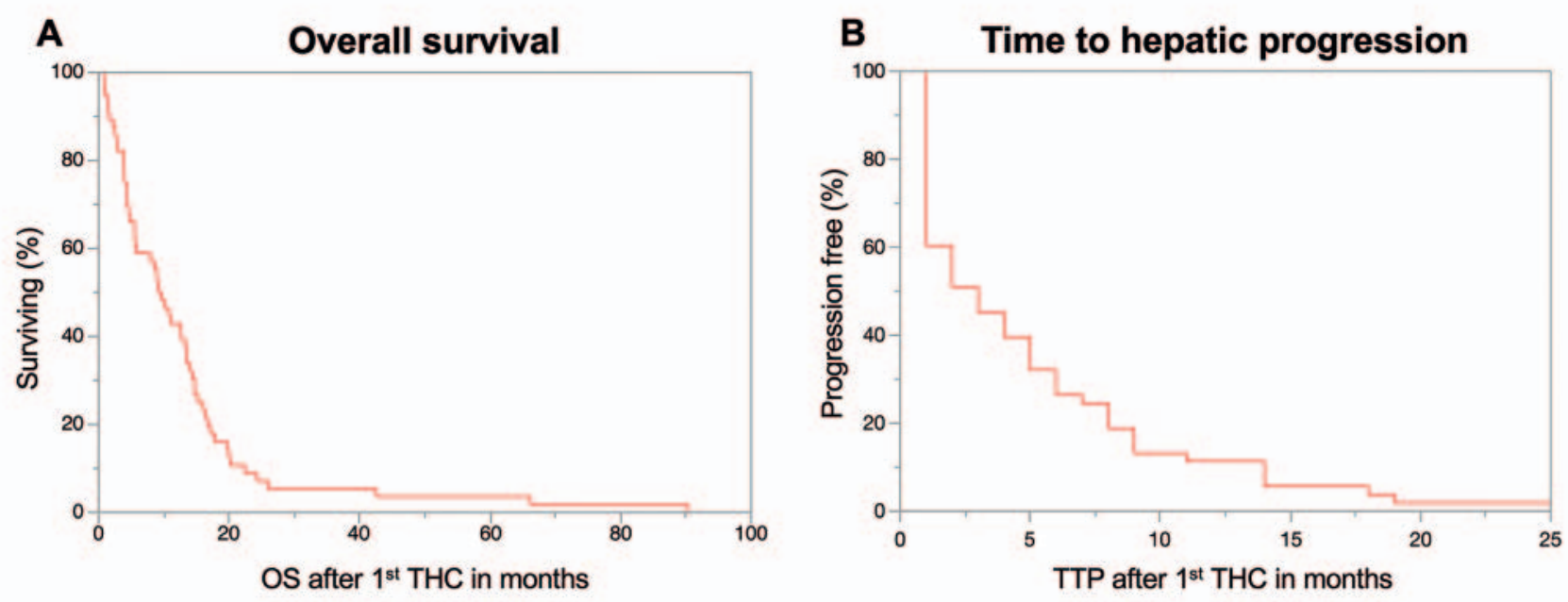

- Fig. 1 Overall survival $\mathbf{a}$ and time to hepatic progression $\mathbf{b}$ after $1^{\text {st }}$ treatment of the entire study cohort. Note: OS= overall survival, $\mathrm{THC}=$ transarterial hepatic chemoperfusion, $\mathrm{TTP}=$ time to progression .

- Abb.1 Gesamtüberleben a und Zeit bis zur hepatischen Progression b nach der 1. Behandlung der gesamten Studienkohorte. OS = Gesamtüberleben; THC = transarterielle hepatische Chemoperfusion; TTP= Zeit bis zur Progression.

- Table 2 Uni- and multivariate analysis of overall survival.

- Tab. 2 Uni- und multivariate Analyse des Gesamtüberlebens.

\begin{tabular}{|c|c|c|c|c|c|c|c|}
\hline \multirow[b]{2}{*}{ subgroups } & & \multirow{2}{*}{$\begin{array}{l}\text { patients in } \\
\text { each group }\end{array}$} & \multirow{2}{*}{$\begin{array}{l}\text { median OS in } \\
\text { months }(95 \% \mathrm{Cl})\end{array}$} & \multicolumn{2}{|l|}{ univariate analysis } & \multicolumn{2}{|c|}{ multivariate analysis } \\
\hline & & & & HR (95\% Cl) & $\mathrm{p}$-value & HR (95\% Cl) & $\mathrm{p}$-value \\
\hline \multirow[t]{3}{*}{ LDH } & normal ( $\leqq 280 \mathrm{U} / \mathrm{L})$ & $18(32 \%)$ & $19.8(16.0-24.3)$ & 1 & \multirow[t]{3}{*}{$<0.0001$} & & - \\
\hline & $\begin{array}{l}\text { intermediate } \\
\text { (> 280-999 U/L) }\end{array}$ & $19(34 \%)$ & $9.7(5.8-12.7)$ & $6.75(5.2-73.5)$ & & $5.0(1.3-25)$ & 0.02 \\
\hline & high $(\geq 1000 \mathrm{U} / \mathrm{L})$ & $19(34 \%)$ & $3.84(1.5-4.3)$ & $77.3(21.9-375.8)$ & & $27.1(5.6-163)$ & $<0.0001$ \\
\hline \multirow[t]{2}{*}{ ALP } & $\leqq 1.5$ ULN & $21(37.5 \%)$ & $16.0(13.3-19.9)$ & 1 & \multirow[t]{2}{*}{$<0.0001$} & 1 & \multirow[t]{2}{*}{0.06} \\
\hline & $>1.5$ ULN & $35(62.5 \%)$ & $4.7(3.8-8.9)$ & $6.8(3.5-13.8)$ & & $2.1(0.97-4.8)$ & \\
\hline \multirow[t]{2}{*}{ leukocytes } & normal & 49 (87.5\%) & $10.8(7.9-14.0)$ & 1 & \multirow[t]{2}{*}{0.0037} & 1 & \multirow[t]{2}{*}{0.83} \\
\hline & $>$ ULN & $7(12.5 \%$ & $2.5(0.8-5.5)$ & $4.2(1.7-9.2)$ & & $1.12(0.41-3.3)$ & \\
\hline \multirow[t]{2}{*}{ GGT } & normal & $29(52 \%)$ & $14.7(12.7-17.7)$ & 1 & \multirow[t]{2}{*}{$<0.0001$} & 1 & \multirow[t]{2}{*}{0.025} \\
\hline & $>$ ULN & $27(48 \%)$ & $4.3(2.5-5.5)$ & $7(3.6-13.6)$ & & $2.9(1.2-7.2)$ & \\
\hline \multirow[t]{2}{*}{ bilirubin } & normal & $48(86 \%)$ & $9.9(5.6-14.3)$ & 1 & \multirow[t]{2}{*}{0.036} & 1 & \multirow[t]{2}{*}{0.002} \\
\hline & $>$ ULN & $8(14 \%)$ & $2.6(0.8-12.7)$ & $2.89(1.23-6.1)$ & & $5.7(1.7-18.2)$ & \\
\hline \multirow[t]{2}{*}{ prior treatment } & no & $27(48 \%)$ & $10.2(5.5-13-5)$ & 1 & \multirow[t]{2}{*}{0.7} & - & \multirow[t]{2}{*}{-} \\
\hline & yes & $29(52 \%)$ & $8.9(3.9-14.7)$ & $1.09(0.6-1.7)$ & & - & \\
\hline \multirow{2}{*}{$\begin{array}{l}\text { extrahepatic } \\
\text { metastases }\end{array}$} & no & $31(55 \%)$ & $13.5(9.0-16.0)$ & 1 & \multirow[t]{2}{*}{0.036} & & \multirow[t]{2}{*}{0.19} \\
\hline & yes & $25(45 \%)$ & $4.7(3.9-9.7)$ & $1.80(1.04-3.1)$ & & $1.5(0.8-2.9)$ & \\
\hline \multirow{2}{*}{$\begin{array}{l}\text { largest liver } \\
\text { lesion }\end{array}$} & $<5 \mathrm{~cm}$ & $21(37.5 \%)$ & 16.7 (13.3-19.9) & 1 & \multirow[t]{2}{*}{$<0.0001$} & 1 & \multirow[t]{2}{*}{0.002} \\
\hline & $\geq 5 \mathrm{~cm}$ & 35 (62.5\%) & $5.5(3.8-8.8)$ & $3.6(2.0-6.8)$ & & $3.7(1.6-8.5)$ & \\
\hline
\end{tabular}



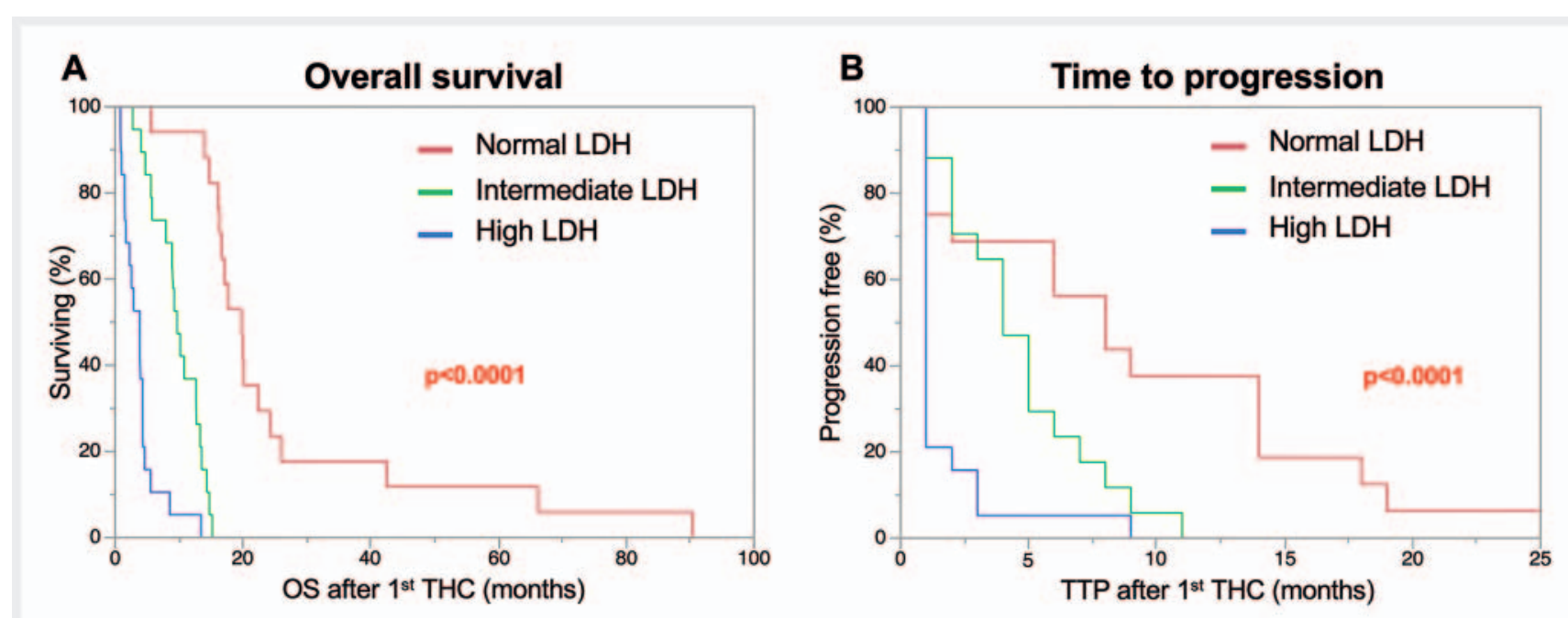

$\checkmark$ Fig. 2 Overall survival a and time to hepatic progression b stratified for normal ( $\leqq 280 \mathrm{U} / \mathrm{L})$, intermediate $(>280$ to $<1000 \mathrm{U} / \mathrm{L})$, and high $(\geqq 1000 \mathrm{U} / \mathrm{L})$ serum LDH levels before $1^{\text {st }}$ transarterial hepatic chemoperfusion. Note: LDH = lactate dehydrogenase, OS overall survival, $\mathrm{THC}=$ transarterial hepatic chemoperfusion, $\mathrm{TTP}=$ time to progression .

- Abb. 2 Gesamtüberleben a und Zeit bis zur hepatischen Progression b stratifiziert für normale ( $\leqq 280 \mathrm{U} / \mathrm{L}$ ), mittlere ( $>280$ bis $<1000 \mathrm{U} / \mathrm{L})$ und hohe ( $\geqq 1000 \mathrm{U} / \mathrm{L}$ ) Serum-LDH-Spiegel vor der 1. transarteriellen hepatischen Chemoperfusion. LDH = Laktatdehydrogenase; OS = Gesamtüberleben; THC = transarterielle hepatische Chemoperfusion; TTP= Zeit bis zur Progression.

with $\mathrm{LDH}$ serum values within the normal range survived the longest with a median OS of 19.8 months ( $95 \% \mathrm{Cl}$ : 16-24.3). In patients with an intermediately elevated LDH (> 280-<1000 U/L), the median overall survival was already cut in half ( 9.7 months; $95 \% \mathrm{Cl}: 5.8-12.7)$, whereas patients with a highly elevated LDH ( $\geqq 1000 \mathrm{U} / \mathrm{L}$ ) survived the shortest amount of time (3.84 months; $95 \%$ Cl: 1.5-4.3) (> Fig. 2a).

Furthermore, liver function test parameters including bilirubin $>$ the upper limit of normal (ULN) $(p=0.036)$, alkaline phosphatase $(A L P)>1.5 \operatorname{ULN}(p<0.0001)$, leukocytes $>\operatorname{ULN}(p=0.0037)$, gamma-glutamyl transferase (GGT) $>$ ULN $(p<0.0001)$, the presence of limited extrahepatic metastases $(p=0.036)$, and size of the largest liver lesion $\geq 5 \mathrm{~cm}(p<0.0001)$ were identified as predictors for worse survival. Multivariate analysis was performed by including statistically significant factors from UVA. Here, intermediate $(p=0.02)$ and high $(p<0.0001)$ LDH levels, bilirubin $(p=0.006)$, GGT $(p=0.021)$, and the size of the largest liver lesion $\geq 5 \mathrm{~cm}(p=0.0017)$ were confirmed as independent predictors for worse survival ( $\triangleright$ Table 2 ). The presence of limited extrahepatic metastases was not identified as an independent OS predictor in MVA $(p=0.19)$. Further details can be found in $>$ Table 2 . Of note, the occurrence of new extrahepatic metastases while undergoing THC was not identified as a statistically significant predictor in UVA (HR: 1.4; $95 \% \mathrm{Cl}$ : 0.78-2.6; $\mathrm{p}=0.26$ ).

$\mathrm{LDH}$ alterations between the $1^{\text {st }}$ and $2^{\text {nd }}$ treatment: The median time between the $1^{\text {st }}$ and $2^{\text {nd }}$ chemoperfusion was 38 days (range: 19-112; $95 \% \mathrm{Cl}$ : 35-43 days; $\mathrm{n}=46$ patients). Patients with a serum $\mathrm{LDH}$ decrease between the $1^{\text {st }}$ and $2^{\text {nd }}$ THC session greater than $10 \%$ survived the longest with a median of 14.6 months (95\% Cl: $1.48-19.9 ; n=17$ ) compared to patients with a relative change of less than $\pm 10 \%$ (9.7 months; $95 \% \mathrm{Cl}: 4.3-13.5$; $n=13$ ) and patients with an increase of $>10 \%$ (4.3 months; $95 \% \mathrm{Cl}$ : $2.5-$ $11 ; n=16), p=0.041$ ( $\vee$ Fig. 3a). Here, a significant statistical difference was only given between the $>10 \%$ decrease and increase groups in UVA ( $p=0.015)$.

$\mathrm{LDH}$ in comparison to best treatment response: The median overall survival according to the best-achieved response was 14.3 months for partial response (PR), 12.7 months for stable disease (SD), and 3.8 months for patients with progressive disease (PD) $(p<0.0001)$ showing similar survival rates compared to baseline LDH levels and LDH change. In MVA, the baseline LDH and best-achieved response both remained significant ( $p<0.0001$ vs. $p=0.003$ ), demonstrating an independent predictive value for each parameter. On the other hand, only the best-achieved response remained a standalone OS predictor in MVA compared to $\mathrm{LDH}$ change between the $1^{\text {st }}$ and $2^{\text {nd }}$ THC session ( $p=0.029$ vs. $p=0.67$ ), showing its superiority.

\section{Treatment response}

General response and TTP: The median time to progression of the study cohort was three months ( $95 \% \mathrm{Cl}: 1-5$ months) ( $\bullet$ Fig. 1b). The best overall achieved response was PR in $27.8 \%(n=15)$, SD in $37 \%(n=20)$, and PD in $19 \%(n=19)$.

Pretreatment prognostic factors: Similar to the median OS, pretreatment serum LDH was identified as the strongest TTP predictor $(p=0.0003)$ with a median of 8 months $(95 \% \mathrm{Cl}: 1-14)$ for patients with $\mathrm{LDH}$ values within the normal range. Patients with an intermediately elevated $\mathrm{LDH}$ progressed after a median of 4 months (95\% Cl: 2-6), whereas most patients with a highly elevated LDH showed progression at the first follow-up ( $\triangleright$ Fig. 2 b, $\triangleright$ Table 3 ).

Aside from LDH, ALP > 1.5 ULN ( $p=0.04)$, GGT > ULN $(p<0.0026)$, and size of the largest liver lesion $\geq 5 \mathrm{~cm}(p<0.011)$ were identified as 

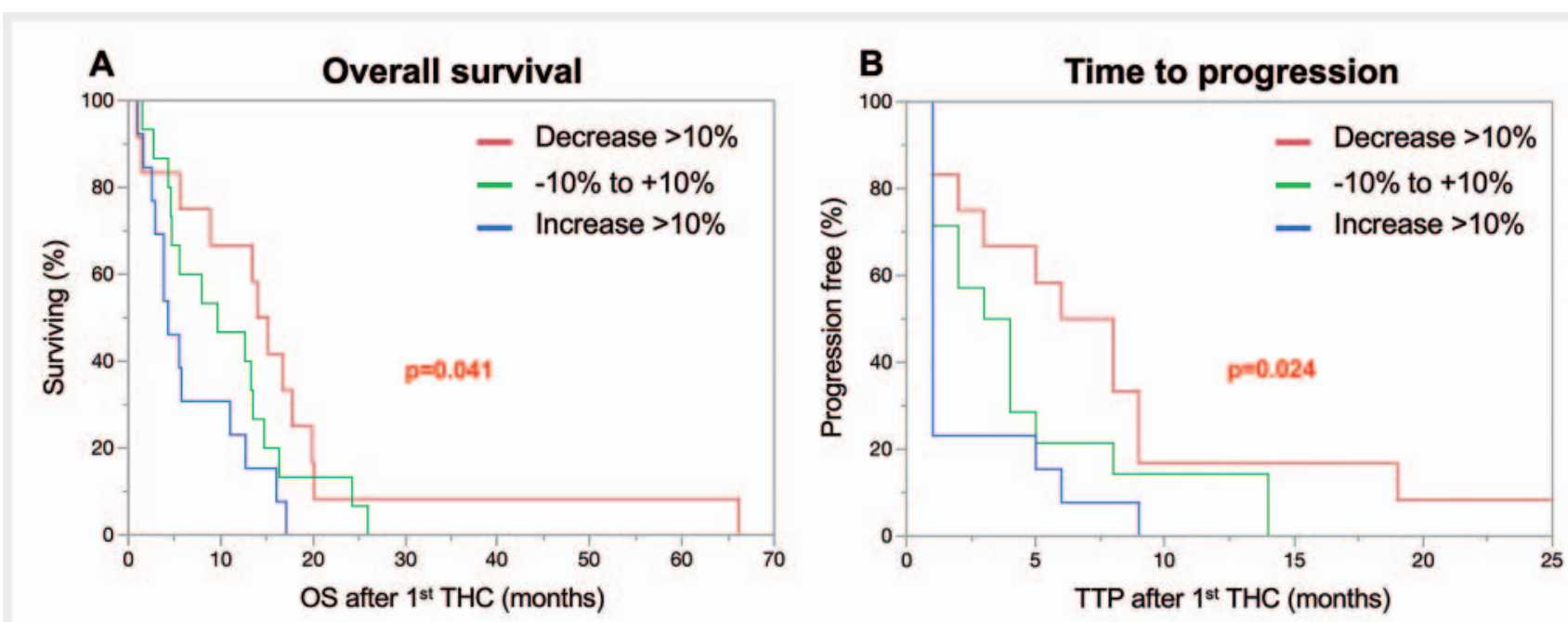

- Fig. 3 Overall survival a and time to progression $\mathbf{b}$ stratified for LDH change between $1^{\text {st }}$ and $2^{\text {nd }}$ transarterial hepatic chemoperfusion. Note: $\mathrm{LDH}=$ lactate dehydrogenase, $\mathrm{OS}=$ overall survival, $\mathrm{THC}=$ transarterial hepatic chemoperfusion, $\mathrm{TTP}=$ time to progression.

- Abb. 3 Gesamtüberleben a und Zeit bis zur Progression b stratifiziert nach der LDH-Änderung zwischen der 1. und 2. transarteriellen hepatischen Chemoperfusion. $\mathrm{LDH}=$ Laktatdehydrogenase; OS = Gesamtüberleben; THC = transarterielle hepatische Chemoperfusion, TTP=Zeit bis zur Progression.

predictors of an earlier time to progression in UVA. In the multivariate analysis, only highly elevated LDH serum levels could be identified as an independent predictor $(p=0.012)$ ( $\triangleright$ Table 3$)$.

$\mathrm{LDH}$ alterations between the $1^{\text {st }}$ and $2^{\text {nd }}$ therapy: Patients with a serum LDH decrease of greater than $10 \%$ had the longest time to progression with a median of 7 months (95\%Cl: $1-9)$ compared to patients with a relative change of less than $10 \%$ (3.5 months; $95 \% \mathrm{Cl}: 1-5)$ and patients with a serum LDH increase $>10 \%$ (1 month; $95 \% \mathrm{Cl}$. .-.), p $=0.024$ ( $\triangleright$ Fig. 3b). UVA only showed a significant difference between the $>10 \%$ increase or decrease groups $(p=0.023)$.

$\mathrm{LDH}$ in comparison to treatment response: The best achieved response rates (PR/SD/PD) were significantly better for low (47\%/41.2\%/11.8\%) than for intermediate $(21.1 \% / 52.6 \% / 26.3)$ and high $\operatorname{LDH}(16.8 \% / 16.7 \% / 66.7 \%)(p=0.005)$. In a direct comparison of the best treatment response vs. baseline $\mathrm{LDH}$, both proved to be strong and independent factors in MVA ( $p=0.023$ vs. $p=0.018$ ) with no clear superiority of one or the other. On the other hand, LDH change could not be confirmed as an independent TTP predictor compared to the best-achieved response in MVA ( $p=0.6$ vs. $p=0.16$ ), thus showing its inferiority.

\section{Discussion}

Despite the tremendous efforts undertaken during the last decades to improve survival times at the stage of metastasized uveal melanoma, treatment remains challenging, with only a little progress having been made. To date, the median overall survival of all patients after the diagnosis of liver metastases is approximately 13.4 months, with a two-year survival rate of $8 \%$. This is similar to our study cohort [10-13]. Thus, aside from developing and evaluating new treatment approaches, identifying patients po- tentially profiting from each therapy is vital for treatment allocation to provide the best care possible. Several prognostic factors were identified in this study as significantly affecting the outcomes of patients treated with THC, with pretreatment serum $\mathrm{LDH}$ being recognized as the strongest and most relevant one.

$\mathrm{LDH}$ is one of the key enzymes in cells for energy production, catalyzing the conversion to lactate from pyruvate in anaerobic environments [14]. As tumors proliferate rapidly with oxygen supply lacking behind demand, LDH plays a crucial role in tumor maintenance and progression under hypoxic conditions [15]. The prognostic relevance of serum LDH in oncology has long been acknowledged in various solid cancers, including cutaneous [16, 17] and uveal melanoma [8], as high serum LDH correlates with a greater tumor burden, a more aggressive phenotype, and shorter survival times [7, 18].

This study demonstrated that patients with serum LDH values within the normal range had the most prolonged survival and time to hepatic tumor progression. On the contrary, an elevated pretreatment serum LDH level above the upper level of normal was strongly associated with shorter survival and time to hepatic progression. Several studies are in agreement with these findings, including a recent meta-analysis based on 29 studies with a total of 912 patients where elevated LDH was associated with worse survival, thereby proving it is the most relevant pretreatment factor [19, 20]. However, despite the robust evidence based on many studies supporting LDH as an independent and robust predictor for OS, Gonsalves et al. could not confirm LDH as a prognostic factor when liver metastases were treated with 1.3-bis (2-chloroethyl)-1-nitrosourea (BCNU) chemoembolization [21].

In our study, serum LDH levels above $1000 \mathrm{U} / \mathrm{L}$ were identified as a highly significant independent predictor for rapid tumor progression in $80 \%$ of patients within one month and a median survival of fewer than four months. Regardless of the primary cancer 
- Table 3 Uni- and multivariate analysis of time to progression.

- Tab.3 Uni- und multivariate Analyse der Zeit zur Progression.

\begin{tabular}{|c|c|c|c|c|c|c|c|}
\hline \multirow[b]{2}{*}{ subgroups } & & \multirow{2}{*}{$\begin{array}{l}\text { patients in } \\
\text { each group }\end{array}$} & \multirow{2}{*}{$\begin{array}{l}\text { median time to } \\
\text { progression in } \\
\text { months }(95 \% \mathrm{Cl})\end{array}$} & \multicolumn{2}{|l|}{ univariate analysis } & \multicolumn{2}{|c|}{ multivariate analysis } \\
\hline & & & & HR (95\% Cl) & p-value & HR (95\% Cl) & p-value \\
\hline \multirow[t]{3}{*}{ LDH } & normal (@280 U/L) & 18 (32\%) & $8(1-14)$ & 1 & \multirow[t]{3}{*}{0.0003} & 1 & - \\
\hline & $\begin{array}{l}\text { intermediate } \\
\text { (>280-999 U/L) }\end{array}$ & $19(34 \%)$ & $4(2-6)$ & $2.43(1.1-5.6)$ & & $1.87(0.7-5.1)$ & 0.22 \\
\hline & high ( $\geq 1000 \mathrm{U} / \mathrm{L}$ ) & 19 (34\%) & $1(.-)$. & $5.3(2.3-12.8)$ & & $4.1(1.36-12.6)$ & 0.012 \\
\hline \multirow[t]{2}{*}{ ALP } & $\leqq 1.5$ ULN & $21(37.5 \%)$ & $5(3-8)$ & 1 & \multirow[t]{2}{*}{0.04} & 1 & \multirow[t]{2}{*}{0.84} \\
\hline & $>1.5$ ULN & 35 (62.5\%) & $1(1-2)$ & $1.85(1.04-3.38)$ & & $1.08(0.49-2.3)$ & \\
\hline \multirow[t]{2}{*}{ leukocytes } & normal & $49(87.5 \%)$ & $3.5(2-5)$ & 1 & \multirow[t]{2}{*}{0.17} & - & \multirow[t]{2}{*}{ - } \\
\hline & $>$ ULN & $7(12.5 \%$ & $1(.-)$. & $1.85(0.75-3.95)$ & & - & \\
\hline \multirow[t]{2}{*}{ GGT } & normal & $29(52 \%)$ & $5.5(4-8)$ & 1 & \multirow[t]{2}{*}{0.0026} & 1 & \multirow[t]{2}{*}{0.43} \\
\hline & $>$ ULN & 27 (48\%) & $1(1-2)$ & $2.52(1.38-4.66)$ & & $1.39(0.61-3.1)$ & \\
\hline \multirow[t]{2}{*}{ bilirubin } & normal & $48(86 \%)$ & $3(1-5)$ & 1 & \multirow[t]{2}{*}{0.36} & - & \multirow[t]{2}{*}{ - } \\
\hline & $>$ ULN & $8(14 \%)$ & $1.5(1-5)$ & $1.45(0.63-2.96)$ & & - & \\
\hline \multirow[t]{2}{*}{ prior treatment } & no & $27(48 \%)$ & $3(1-6)$ & 1 & \multirow[t]{2}{*}{0.6} & - & \multirow[t]{2}{*}{ - } \\
\hline & yes & $29(52 \%)$ & $2.5(1-5)$ & $1.16(0.65-2)$ & & & \\
\hline \multirow{2}{*}{$\begin{array}{l}\text { extrahepatic } \\
\text { metastases }\end{array}$} & no & 31 (55\%) & $5(2-7)$ & 1 & \multirow[t]{2}{*}{0.165} & - & \multirow[t]{2}{*}{-} \\
\hline & yes & $25(45 \%)$ & $1(1-3)$ & $1.48(0.85-2.58)$ & & - & \\
\hline \multirow{2}{*}{$\begin{array}{l}\text { largest liver } \\
\text { lesion }\end{array}$} & $<5 \mathrm{~cm}$ & $21(37.5 \%)$ & $6(2-9)$ & 1 & \multirow[t]{2}{*}{0.011} & 1 & \multirow[t]{2}{*}{0.34} \\
\hline & $\geq 5 \mathrm{~cm}$ & 35 (62.5\%) & $1.5(1-3)$ & $2.1(1.19-4.0)$ & & $1.44(0.68-3.1)$ & \\
\hline
\end{tabular}

location, such high levels have previously been shown to limit overall survival, strongly indicating aggressive tumor biology and terminal cancer [7]. Thus, it may even be questioned if patients with $\mathrm{LDH}$ values $>1000 \mathrm{U} / \mathrm{L}$ will even benefit from treatment or if palliative care or study inclusion for evaluating novel treatment approaches should be preferred. Moreover, compared to more specific tumor markers such as osteopontin, neuron-specific enolase, and S100- $\beta$, LDH bears the advantage of being broadly available and is associated with low costs [22]. Moreover, the prognostic value of pretreatment $L D H$ can be underlined by the fact that it greatly correlates with the best-achieved response and survival times but is already available before the $1^{\text {st }}$ treatment.

The evaluation of relative $\mathrm{LDH}$ changes between the $1^{\text {st }}$ and $2^{\text {nd }}$ chemoperfusion sessions revealed that patients with decreasing LDH values greater than $10 \%$ had a more prolonged overall survival and a longer time to progression. However, the prognostic significance on OS $(p=0.041)$ and TTP $(p=0.24)$ is weaker compared to the LDH baseline $(p<0.0001)$ and seems inferior to conventional imaging-based response assessment. Liu et al. discovered that patients who had normalized LDH values following treatment had a significantly longer overall survival even if pretreatment values were $>1000 \mathrm{U} / \mathrm{L}$ [7]. Although interesting, subgroup analysis of $\mathrm{LDH}$ changes in this cohort regarding the prognostic value of this high-risk group was not considered meaningful due to a lack of statistical power.

Aside from LDH, liver function test parameters are routinely assessed during follow-up as increasing values are linked to a higher likelihood for the presence and extent of liver metastases negatively correlating with survival times. Nonetheless, sensitivity and prognostic value lag behind serum LDH and a non-tumorous increase due to, e. g., viral hepatitis, cholestasis, cirrhosis, drugs, and infections, limits specificity [23]. Regarding time to progression, none of these parameters were relevant in multivariate analysis as they reflect liver function rather than tumor biology, underlining the subordinate prognostic relevance.

Although the presence of extrahepatic metastases did prove to be a factor negatively affecting overall survival in the UVA, it could not be confirmed in the MVA. Moreover, the occurrence of new extrahepatic metastases after treatment start did not impact survival. The patients in this study had prevalent liver disease and usually died from liver failure due to liver tumor progression before extrahepatic metastases could become relevant [24]. Thus, limited extrahepatic disease can generally be neglected when the degree of liver involvement is considered the primary limiting survival factor. 
Recently, the technique of chemosaturation with melphalan has been developed and evaluated for the treatment of uveal melanoma liver metastases [25-27]. Briefly, in addition to melphalan infusion into the liver arteries, the liver's venous blood is harvested by placing a double-balloon catheter into the inferior vena cava to remove the residual melphalan by hemofiltration to allow for higher hepatic melphalan concentrations while limiting extrahepatic exposure. The reported median OS values in these studies were 9.6 [25], 15.3 [26], and 27.4 [27] months. Among these studies, only Karydis et al. evaluated pretreatment factors showing better survival for patients with a normal LDH, lower tumor burden, and absence of extrahepatic disease at treatment onset in univariate analysis. These results are similar to those found in our population, but the result from multivariate analysis to confirm independence was not published [26]. Also, the reported adverse events after chemosaturation [25-27] were more frequent and more severe than those reported for conventional chemoperfusion [9].

On the other hand, the mean number of treatments with 1.52.6 sessions for the chemosaturation group was considerably lower compared to our mean treatment number of 4.7 per patient [25-27]. However, as the German Institute for Medical Documentation and Information (DIMDI) estimates the cost per treatment session for chemosaturation to be around $21000 €$ vs. $1000 €$ for chemoperfusion, the overall treatment costs are considerably lower for chemoperfusion [28]. Nonetheless, a study comparing efficacy, safety, and cost-effectiveness is warranted to identify which patients may benefit the most from each treatment option.

Several study limitations should be acknowledged. The retrospectively enrolled patients were limited to one institution, and study protocols may differ from other institutions restricting the transferability of findings to different patient cohorts. Moreover, the sample size did not allow for in-depth subgroup analysis. Thus, the prognostic value of pretreatment LDH levels should be confirmed in a larger, multicenter design.

\section{Conclusion}

In conclusion, a normal serum LDH level, and to a smaller extent, an LDH decrease greater than $10 \%$ between the $1^{\text {st }}$ and $2^{\text {nd }}$ treatment are important positive determinants of survival and time to progression in patients with uveal melanoma liver metastases treated with transarterial hepatic chemoperfusion. Moreover, better survival is related to low pretreatment bilirubin, GGT, and smaller size of the largest liver lesion. On the contrary, existing or newly occurring extrahepatic lesions after the $1^{\text {st }}$ treatment were not prognostically relevant. Thus, these pretreatment factors may allow for the identification of patients who may have the most benefit from transarterial hepatic chemoperfusion.

\section{Conflict of Interest}

The authors declare that they have no conflict of interest.

\section{References}

[1] Carvajal RD, Schwartz GK, Tezel T et al. Metastatic disease from uveal melanoma: treatment options and future prospects. $\mathrm{Br}$ J Ophthalmol 2017; 101: 38-44

[2] Singh AD, Turell ME, Topham AK. Uveal melanoma: trends in incidence, treatment, and survival. Ophthalmology 2011; 118: 1881-1885

[3] Virgili G, Gatta G, Ciccolallo L et al. Incidence of uveal melanoma in Europe. Ophthalmology 2007; 114: 2309-2315

[4] Rowcroft A, Loveday BPT, Thomson BNJ et al. Systematic review of liver directed therapy for uveal melanoma hepatic metastases. HPB (Oxford) 2019. doi:10.1016/j.hpb.2019.11.002

[5] Rietschel P, Panageas KS, Hanlon C et al. Variates of survival in metastatic uveal melanoma. J Clin Oncol 2005; 23: 8076-8080

[6] Leyvraz S, Piperno-Neumann S, Suciu S et al. Hepatic intra-arterial versus intravenous fotemustine in patients with liver metastases from uveal melanoma (EORTC 18021): a multicentric randomized trial. Ann Oncol 2014; 25: 742-746

[7] Liu R, Cao J, Gao X et al. Overall survival of cancer patients with serum lactate dehydrogenase greater than $1000 \mathrm{IU} / \mathrm{L}$. Tumour Biol 2016; 37: 14083-14088

[8] Nicholas MN, Khoja L, Atenafu EG et al. Prognostic factors for first-line therapy and overall survival of metastatic uveal melanoma: The Princess Margaret Cancer Centre experience. Melanoma Res 2018; 28: 571-577

[9] Heusner TA, Antoch G, Wittkowski-Sterczewski A et al. Transarterial hepatic chemoperfusion of uveal melanoma metastases: survival and response to treatment. Rofo 2011; 183: 1151-1160

[10] Krantz BA, Dave N, Komatsubara KM et al. Uveal melanoma: epidemiology, etiology, and treatment of primary disease. Clin Ophthalmol 2017; 11: $279-289$

[11] Diener-West M, Reynolds SM, Agugliaro DJ et al. Development of metastatic disease after enrollment in the COMS trials for treatment of choroidal melanoma: Collaborative Ocular Melanoma Study Group Report No. 26. Arch Ophthalmol 2005; 123: 1639-1643

[12] Kujala E, Makitie T, Kivela T. Very long-term prognosis of patients with malignant uveal melanoma. Invest Ophthalmol Vis Sci 2003; 44: 46514659

[13] Kuk D, Shoushtari AN, Barker CA et al. Prognosis of Mucosal, Uveal, Acral, Nonacral Cutaneous, and Unknown Primary Melanoma From the Time of First Metastasis. Oncologist 2016; 21: 848-854

[14] Jin Y, Ye X, Shao L et al. Serum lactic dehydrogenase strongly predicts survival in metastatic nasopharyngeal carcinoma treated with palliative chemotherapy. Eur J Cancer 2013; 49: 1619-1626

[15] Rademakers SE, Lok J, van der Kogel AJ et al. Metabolic markers in relation to hypoxia; staining patterns and colocalization of pimonidazole, HIF-1alpha, CAIX, LDH-5, GLUT-1, MCT1 and MCT4. BMC Cancer 2011; 11: 167

[16] Egberts F, Kotthoff EM, Gerdes S et al. Comparative study of YKL-40, $\mathrm{S}-100 \mathrm{~B}$ and LDH as monitoring tools for Stage IV melanoma. Eur J Cancer 2012; 48: 695-702

[17] Agarwala SS, Keilholz U, Gilles E et al. LDH correlation with survival in advanced melanoma from two large, randomised trials (Oblimersen GM301 and EORTC 18951). Eur J Cancer 2009; 45: 1807-1814

[18] Walenta S, Mueller-Klieser WF. Lactate: mirror and motor of tumor malignancy. Semin Radiat Oncol 2004; 14: 267-274

[19] Khoja L, Atenafu EG, Suciu S et al. Meta-analysis in metastatic uveal melanoma to determine progression free and overall survival benchmarks: an international rare cancers initiative (IRCI) ocular melanoma study. Ann Oncol 2019; 30: 1370-1380

[20] Shibayama Y, Namikawa K, Sone M et al. Efficacy and toxicity of transarterial chemoembolization therapy using cisplatin and gelatin sponge 
in patients with liver metastases from uveal melanoma in an Asian population. Int J Clin Oncol 2017; 22: 577-584

[21] Gonsalves CF, Eschelman D], Thornburg B et al. Uveal Melanoma Metastatic to the Liver: Chemoembolization With 1.3-Bis-(2-Chloroethyl)-1Nitrosourea. Am J Roentgenol 2015; 205: 429-433

[22] Barak V, Frenkel S, Kalickman I et al. Serum markers to detect metastatic uveal melanoma. Anticancer Res 2007; 27: 1897-1900

[23] Mouriaux F, Diorio C, Bergeron D et al. Liver function testing is not helpful for early diagnosis of metastatic uveal melanoma. Ophthalmology 2012; 119: 1590-1595

[24] Valpione S, Moser JC, Parrozzani R et al. Development and external validation of a prognostic nomogram for metastatic uveal melanoma. PLoS One 2015; 10: e0120181
[25] Vogl T], Koch SA, Lotz G et al. Percutaneous Isolated Hepatic Perfusion as a Treatment for Isolated Hepatic Metastases of Uveal Melanoma: Patient Outcome and Safety in a Multi-centre Study. Cardiovasc Intervent Radio 2017; 40: 864-872

[26] Karydis I, Gangi A, Wheater MJ et al. Percutaneous hepatic perfusion with melphalan in uveal melanoma: A safe and effective treatment modality in an orphan disease. J Surg Oncol 2018; 117: 1170-1178

[27] Artzner C, Mossakowski O, Hefferman G et al. Chemosaturation with percutaneous hepatic perfusion of melphalan for liver-dominant metastatic uveal melanoma: a single center experience. Cancer Imaging 2019; 19: 31

[28] Information DGIfMDa. Differenzierung des OPS-Kodes 8-549 für die Organperfusion mit Chemotherapeutika. 2018 